\title{
Mild form of Hunter's syndrome: clinical delineation based on 31 cases
}

\author{
I D YOUNG AND P S HARPER \\ Department of Medicine, Section of Medical Genetics, University Hospital of Wales, Cardiff
}

SUMMARY The clinical features are described in 31 cases of the mild form of Hunter's syndrome (mucopolysaccharidosis II) ascertained in the British Isles. The mean age at onset was $4 \cdot 3$ years and at death was 21.7 years. Each patient had a large head and short stature. Umbilical and inguinal herniae were recorded in $95 \%$ and $61 \%$ of the cases. Evidence of cardiac disease was found in $91 \%$; this was the most common cause of death. All of the patients suffered from frequent upper or lower respiratory tract infection. Middle airways obstruction proved to be a particular hazard. A high incidence of sensorineural deafness and unexplained papilloedema was noted. The importance of regular health care for these individuals is stressed.

The demonstration of heterogeneity within the geneiic mucopolysaccharidoses marks one of the major landmarks in contemporary knowledge of hereditary disease in man. There is now abundant evidence to suggest that Hunter's syndrome, first described in $1917^{1}$ and subsequently shown to be sex-linked, ${ }^{2}$ is heterogeneous, with patients falling into two groups, labelled 'mild' and 'severe' depending upon the presence or absence of progressive mental retardation. ${ }^{34}$

We have recently completed a national survey of Hunter's syndrome, the genetic aspects of which have been presented elsewhere. ${ }^{56}$ This paper describes the clinical features in a large group of patients with the fairly rare mild form of the disease.

\section{Patients ascertained}

Following an approach by letter to paediatricians throughout the British Isles, details were obtained concerning 22 definite and 9 probable cases of mild Hunter's syndrome. The diagnosis in the former was based upon reduced activity of iduronate sulphatase, ${ }^{7}$ and in the latter upon a characteristic phenotype, with clear corneae, and excessive mucopolysacchariduria.

At the time of ascertainment, 14 of the patients were dead. Ten patients were personally examined: details of the remainder were obtained from hospital records and discussion with living relatives. Photographs of 10 of the study patients are shown in Fig. 1. Cases $1,{ }^{8} 2,{ }^{9} 18-22,{ }^{10}$ and $25-26^{11} 12$ have been reported elsewhere.
All the patients were male and none had reproduced at the time of the study.

\section{Results}

Clinical features of the 31 patients are summarised in Table 1. During the period of maximum ascertainment the incidence of the disorder was 1 in 579282 male live births $(0.173$ per 100000$)$ and the prevalence 1 in 3.17 million males and females (0.065 per 100000 males). These data show the rarity of the condition.

General appearance. As shown (Fig. 1) the patients tend to share a characteristic facies with prominent supraorbital ridges, large nose with flared nares, patulous lips, and generous jowls with prognathism. Their short stature, hirsutism, abdominal protruberance, joint contractures, and loping gait endow these individuals with an unfortunate ape-like appearance. This cruel physiognomy, made worse by chronic ill health, often lead to serious emotional distress as documented in full elsewhere. ${ }^{13}$

Natural history. The average age of onset, defined as that age when either the parents or a health care professional became seriously concerned about the boy's health, was 4.3 years. The mean age of death for the 14 dead patients was 21.7 years.

The most common presenting symptom or sign was facial appearance, so that the diagnosis was usually first suspected by a paediatrician seeing the child for a fairly trivial reason. As shown (Table 1) the most common cause of death was cardiac failure. 


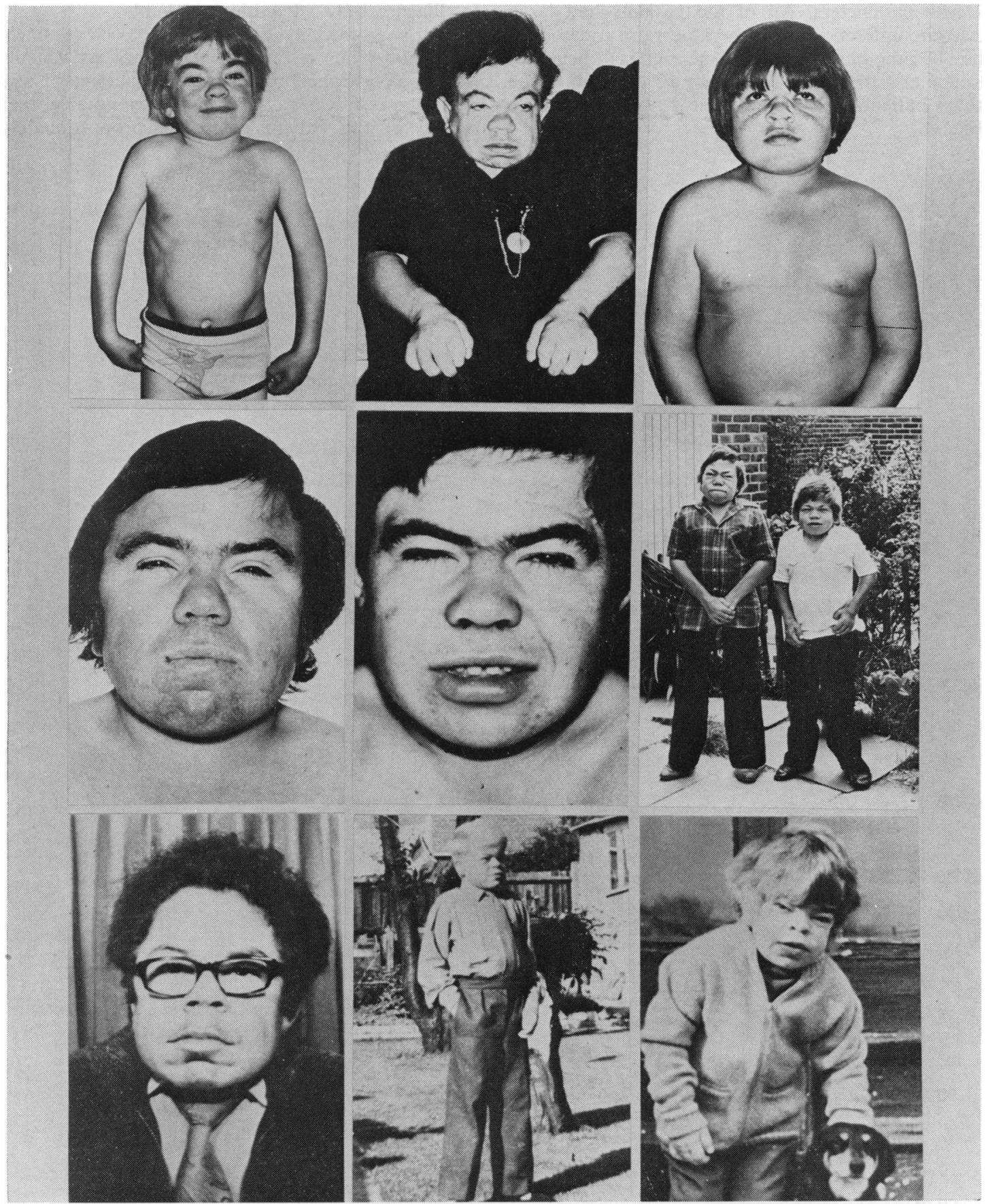

Fig. 1 (Top row left to right) Case 8 at 6 years, Case 10 at 22 years, and Case 60 at 15 years. (Middle row) Case 1 at 31 years, Case 2 at 20 years, Case 23 at 20 years, and Case 24 at 17 years. (Bottom Row) Case 49 at 22 years, Case 50 at 17 years, and Case 51 at 12 years. Cases 23 and 24 are nephews of Cases 25 and 26 who have been described elsewhere. ${ }^{11} 12$ 
Growth parameters. All of the patients had large head circumferences which became more apparent as they became older (Fig. 2). Linear growth began to decline at 4 to 6 years so that by 12 years all of the study patients had fallen below the 3 rd centile (Fig. 3).
Intelligence. By definition patients with mild Hunter's syndrome have normal or relatively normal intelligence. Formal intelligence assessments had been performed in 9 of the study patients. These results are shown in Table 2 . It is notable that several of the patients scored disproportionately

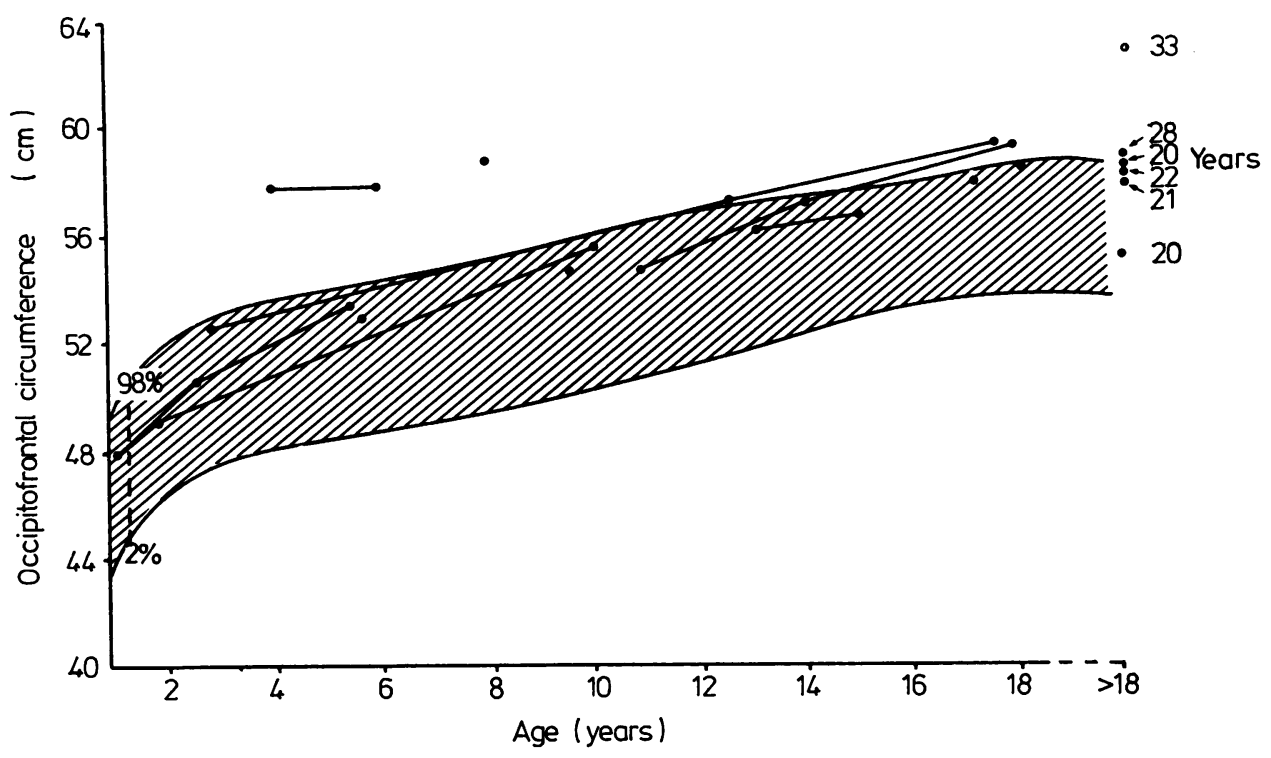

Fig. 2 Head growth in study patients. Note increase with advancing years.

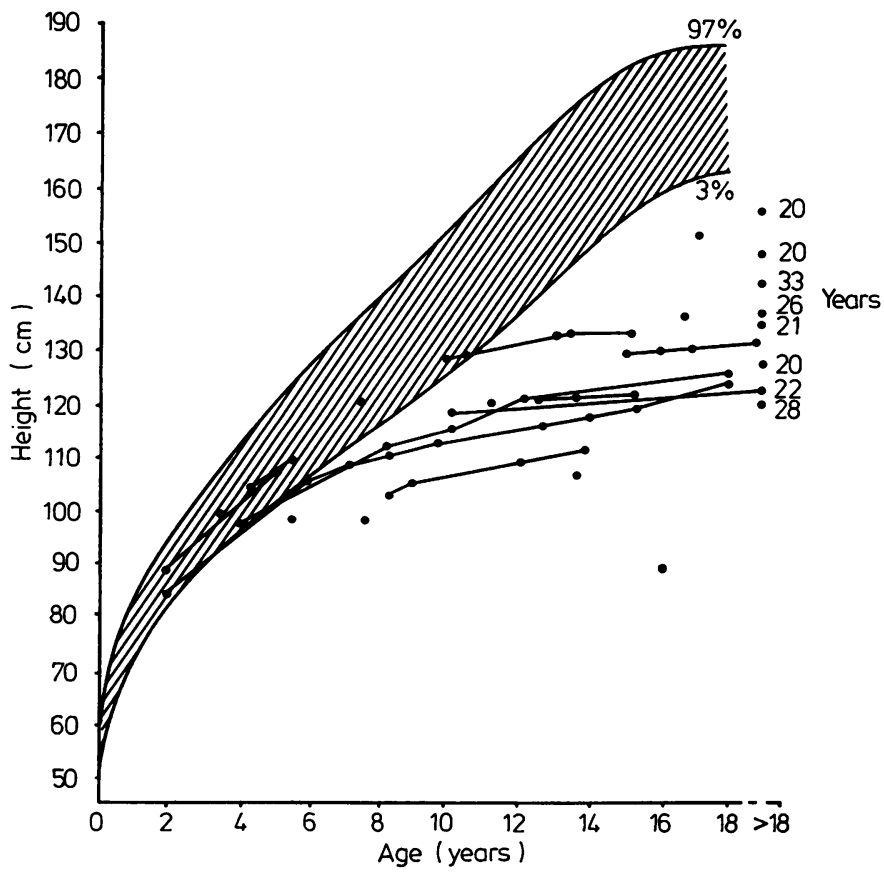

Fig. 3 Linear growth in study patients. 
Mild form of Hunter's syndrome: clinical delineation based on 31 cases 831

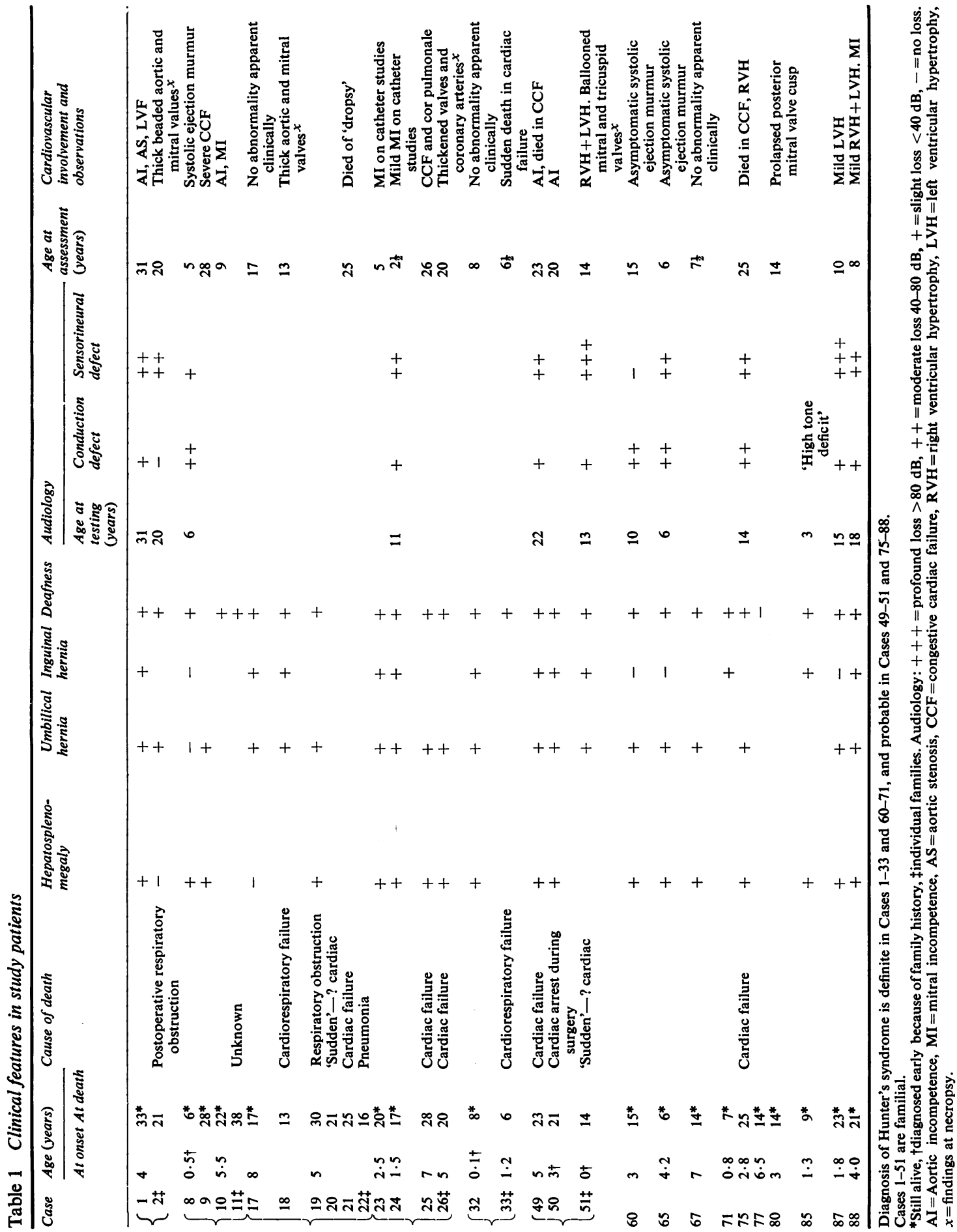


Table 2 Results of formal IQ assessments in study patients

\begin{tabular}{|c|c|c|c|c|c|c|}
\hline Case & $\begin{array}{l}\text { Chrono- } \\
\text { logical age } \\
\text { (years) }\end{array}$ & $\begin{array}{l}\text { Reading } \\
\text { age } \\
\text { (years) }\end{array}$ & $\begin{array}{l}\text { Perfor- } \\
\text { mance } \\
I Q\end{array}$ & $\begin{array}{l}\text { Verbal } \\
I Q\end{array}$ & $\begin{array}{c}\text { Full } \\
I Q\end{array}$ & Test \\
\hline $\begin{array}{l}1 \\
10 \\
17 \\
\\
32 \\
33 \\
51 \\
65 \\
75\end{array}$ & $\begin{array}{l}31 \\
9 \cdot 8 \\
4 \\
10 \cdot 9 \\
4 \\
2 \\
13 \\
5 \\
4 \cdot 6 \\
8 \\
\\
9 \\
14 \cdot 6 \\
5 \cdot 2 \\
7 \cdot 4 \\
13 \cdot 2\end{array}$ & $\begin{array}{l}6 \cdot 3 \\
8 \cdot 3\end{array}$ & $\begin{array}{l}82 \\
115-130\end{array}$ & $<115$ & $\begin{array}{r}67 \\
42 \\
55 \\
50 \\
\\
87 \\
90 \\
106\end{array}$ & $\begin{array}{l}\text { WISA } \\
\text { SB } \\
\text { MP } \\
\text { WISC } \\
\text { Unknown } \\
\text { Unknown } \\
\text { WISC } \\
\text { WISC } \\
\text { Unknown } \\
\text { Columbia } \\
\text { SB } \\
\text { Columbia } \\
\text { TM } \\
\text { WISC } \\
\text { WISC }\end{array}$ \\
\hline
\end{tabular}

WISC/A $=$ Wechsler intelligence tests for children/adults, $\mathbf{M P}=$ Merrill Palmer, $\mathbf{S B}=$ Stanford Binet, $\mathbf{T M}=$ Terman Merrill.

badly on tests of verbal and reading abilities. The unusual results in Cases 17 and 75 have been discussed elsewhere. ${ }^{5}$

An additional indicator of intelligence is given by academic achievements and occupational history. One patient passed the ' 11 plus' and subsequently worked as a jeweller's engraver. Six of the study group had passed the driving test: two worked as van drivers, and a third ran a building office for over 7 years. One patient was unable to find work despite having passed several sutjects at $O$ and CSE level.

Gastrointestinal system. Nearly all patients showed significant disease on abdominal examination. Hepatosplenomegaly was documented in 18 out of 20 cases, being present as early as 11 months in one and as late as $\mathbf{3 3}$ years in another. Necropsy studies in Case 2 showed a liver of normal size with only mild splenomegaly. Definite hepatosplenomegaly was noted in his cousin, Case 1, so that the presence or absence of this feature does not appear to be a familial characteristic.

All of the study patients about whom information could be obtained, other than Case 8 , were noted to have an umbilical hernia at some stage in their illness. This was often present at birth and rarely troublesome. In Case 23 emergency surgery was required for incarceration and subsequent repair was needed on two occasions. Inguinal herniae were noted in $61 \%$ of the cases, being bilateral in $33 \%$, right sided in $17 \%$, and left sided in $11 \%$. In $33 \%$ of these patients the hernia was present at birth or in early infancy. Recurrence after surgery occurred in 2 patients. An incisional hernia occurred in one patient after the removal of an inflamed appendix at age 13 years.

Cardiovascular system. Evidence of cardiac disease was present in 21 out of 23 patients about whom information could be obtained. This is summarised in Table 2. Valvular disease was particularly common often existing from early childhood as revealed by the catheter studies performed in Cases 23 and 24 at ages 5 and $2 \frac{1}{2}$ years. The importance of cardiac disease in this disorder is reflected by the fact that it was the most common cause of death among the study patients, several of whom had been treated with digoxin and diuretics with only limited success.

Respiratory system. All of the study patients had a history of frequent upper respiratory infections including rhinitis, tonsillitis, laryngitis, and otitis media, with chronic muco-purulent nasal discharge. Tonsils and adenoids were removed from 14 of 19 patients at a modal age of 4 years. Lower respiratory infections tended to be less frequent in these patients, but when present proved life threatening. Often an element of cardiac failure supervened. During these dyspnoeic episodes the expectoration of profuse secretions proved a major hazard.

A curious finding, possibly related to the rigidity of the chest wall, was the presence of bronchial breathing in 4 cases, in the absence of other signs of active pulmonary disease. All of the patients showed reduced chest expansion due to the splinting effect of a rigid rib cage and abdominal distension. Two of the older patients spontaneously volunteered that they were unable to swim and in particular float.

One of the most sinister problems in these patients was their propensity to middle airways obstruction. Serious problems had occurred during attempted intubation in 4 cases, one of whom died. Of the 10 cases personally examined, all but one, the youngest, had a husky or hoarse low pitched voice which became more noticeable with advancing years. In these patients there was no other evidence of relevant cranial nerve disturbance.

Hearing. Deafness was common (Table 1) and in 3 this was the main complaint. The hearing deficit, often first noted in early childhood, consisted of both conductive and sensorineural components. This is well illustrated in Fig. 4 which shows audiograms recorded from Case 17 at age 7 years, shortly before and after bilateral myringotomy and insertion of grommets. These audiograms clearly show the benefit gained by regular drainage of the chronic glue ear occurring as a result of persistent Eustachian tube dysfunction associated with adenoidal hypertrophy. Prompt and appropriate antibiotic and 
decongestant therapy would seem to be indicated to try to prevent this unwelcome legacy of chronic upper airways disease.

Neurological involvement. Blurring of the disc margins was noted in 6 of the 10 cases personally examined. In one of these patients the presence of true papilloedema was confirmed by fluorescein angiography. ${ }^{8}$ In two others the disc blurring was attributed to pseudopapilloedema-that is severe hypermetropia with a small pink disc. None of these patients had seriously impaired vision or other evidence of raised intracranial pressure.

Electroretinography in 3 cases at ages 13, 21, and 33 years showed a reduced amplitude response. In

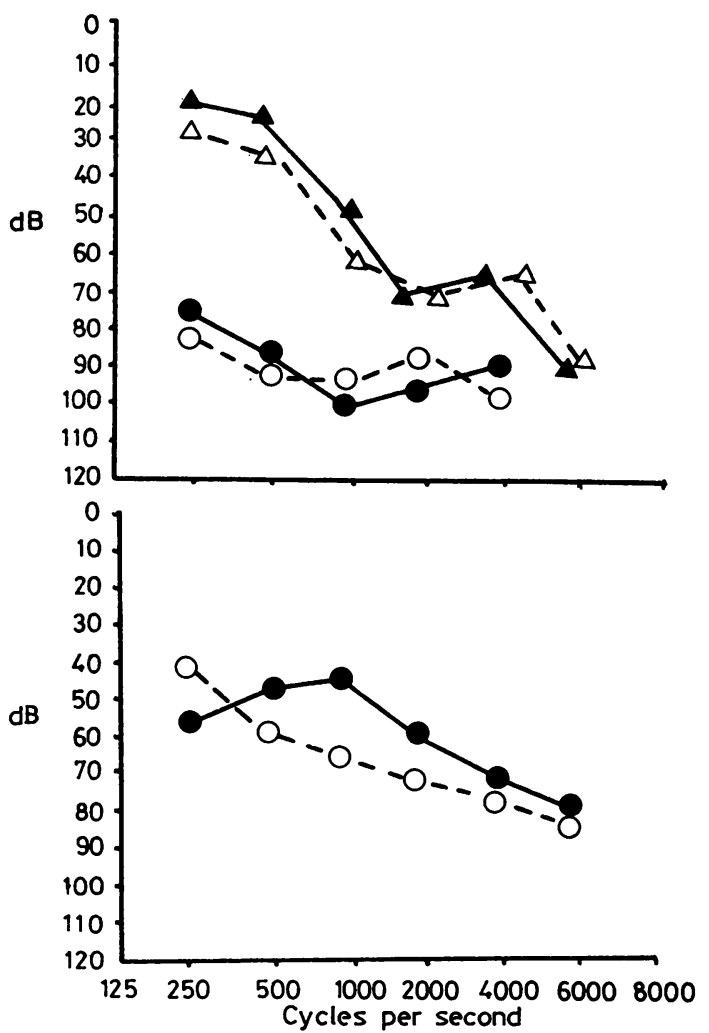
$\Delta$ Right masked bone conduction
$\Delta$ Left masked bone conduction
- Right air conduction
- Left air conduction

Fig. 4 Audiograms in Case 17 at age 7 years (a) before and (b) after bilateral myringotomy and insertion of grommets. Masked bone conduction tracing indicates the overall hearing potential. two of them the visually evoked responses were also of low amplitude and poorly defined. Two other patients in the study complained of poor nocturnal vision.

Other than papilloedema few of the study patients showed evidence of serious neurological disturbance. Only one had a history of fits, having sustained a single grand mal convulsion with residual hemiparesis at age 12 years. The hemiparesis recovered within 3 weeks. This individual died 18 years later with no evidence of progressive neurological disease. The most serious problem encountered was an unexplained slowly progressive quadriparesis which first presented in a 27-year-old patient after a fall down a flight of stairs. At the time of examination 2 years later, the patient was almost totally helpless although fully alert and orientated. Other than lower spinal plain radiographs which showed no bone injury, this man's quadriparesis had not been investigated.

Bilateral carpal tunnel syndrome had been treated in 4 patients at ages $13,19,20$, and 21 years. In one of these individuals gross sensory changes were present with trophic lesions on the fingers.

Locomotor system. Evidence of widespread joint involvement was present in all the study patients. This was clearly manifest in the two youngest boys and became increasingly severe in the older individuals, the oldest of whom suffered severe bilateral hip pain associated with radiological evidence of extensive osteoarthritis at age 31 years.

Spinal involvement tended to be minor with loss of normal curvature. Four patients showed a mild thoraco-lumbar kyphosis, non-progressive in nature. The joints showing most severe involvement in decreasing order of severity were those in the hands, elbows, shoulders, hips, knees, wrists, and ankles. The well recognised 'claw-like' changes were apparent by 5 years, and with advancing age the hands took on a spade-like appearance being broad and thick with stubby clawed digits. These features are apparent in Fig. 5 which shows the hands of the oldest encountered living patient at the age of 31 years. This picture also shows early atrophy of the thenar musculature.

\section{Discussion}

It is evident that individuals with this disorder are subject to extensive multi-system disease, due primarily to the functional disturbance generated by the cellular accumulation of excessive oligosaccharides. However the pathogenesis of some of the more insidious and invidious complications is not entirely clear. 


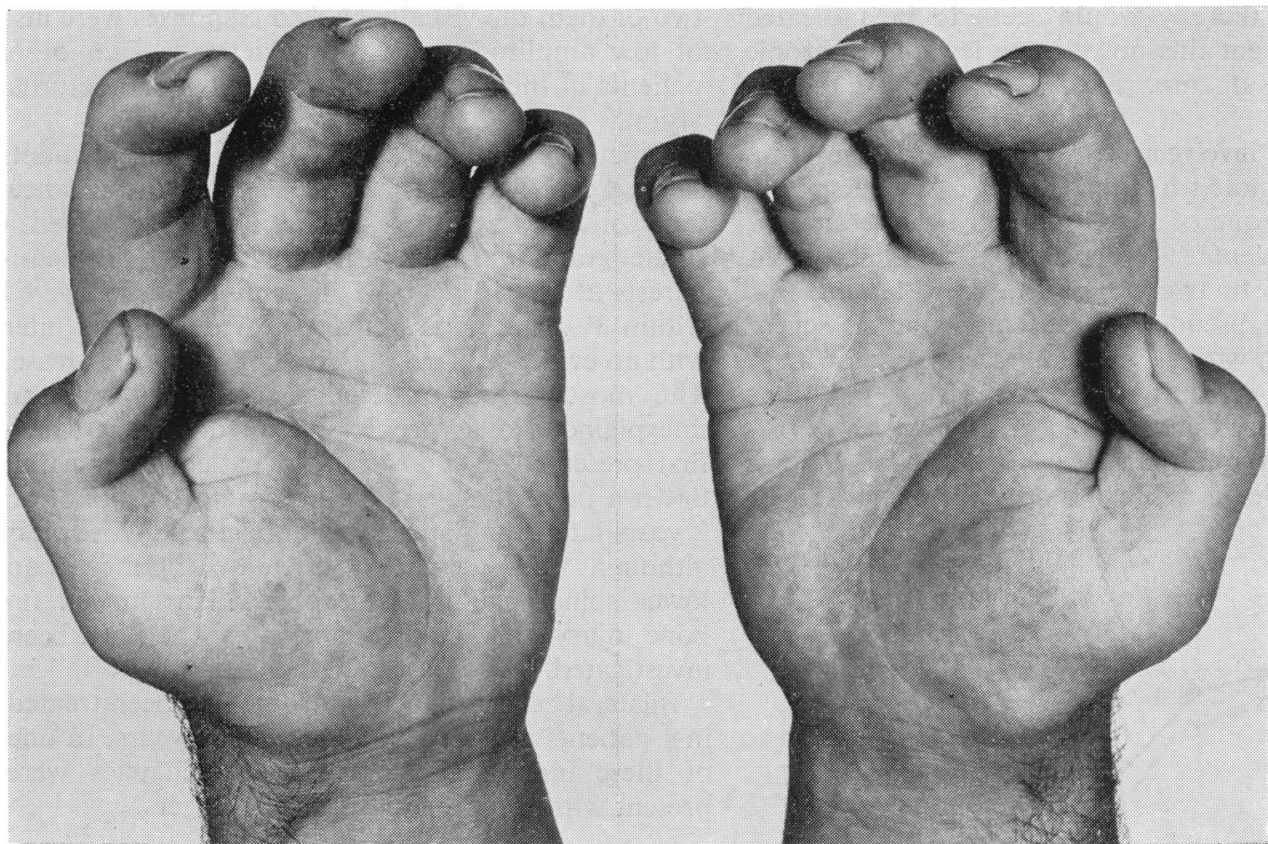

Fig. 5 The hands of Case 1 at 31 years. Note the spade-like appearance with typical 'claw' deformity.

Dwarfism, for example, was a consistent finding in the study group with the average height of 11 patients aged over 18 years being $134.5 \mathrm{~cm}$. The cause of this dwarfism is unknown. Osseous growth plate disturbance may be partially responsible since skeletal involvement in the form of dysostosis multiplex is well known in the mucopolysaccharidoses, in which both osteocytes and chondrocytes may show storage abnormalities. ${ }^{14}$ Pituitary function may also be impaired. Necropsy findings in Case 18 showed a paucity of eosinophilic cells plus extensive 'degenerate' cells in the pituitary. ${ }^{10}$ In another well documented case of mild Hunter's syndrome, vacuolated cells were found in the anterior lobe of the pituitary at necropsy..$^{15}$ Although they have not been described in mild Hunter's syndrome, arachnoid cysts have been reported in the pituitary fossa in other forms of mucopolysaccharidosis, ${ }^{16}$ and their presence may well further compromise pituitary function.

The explanation for the macrocephaly may also be multifactorial, and include thick skin, bushy scalp hair, calvarial thickening with frontal bossing, meningeal hypertrophy, cerebral enlargement, and possibly mild hydrocephaly. Computerised tomography in Case 1 at age 31 years showed normal lateral and 3rd ventricles with a dilated 4th ventricle. In his cousin (Case 2) examination at necropsy showed the brain to be enlarged $(1800 \mathrm{~g})$ with 'congested' meninges but no other apparent abnormality. Reports suggest that hydrocephalus doesco not normally occur in mild Hunter's syndrome, the ? exception being a child, ${ }^{17}$ in whom there was failure of reabsorption of cerebrospinal fluid because of leptomeningeal thickening.

The high incidence of inguinal and umbilical herniae in Hunter's syndrome may be due at least in part to underlying abnormalities in connective tissue. An increased quantity of mucopolysaccharide has been noted in the connective tissue from bone, cartilage, and respiratory tract obtained from a 32year-old man with probable mild Hunter's syndrome who died in a road accident. ${ }^{18}$ It was also noted that collagen-mucopolysaccharide bonds in his bone, cartilage, skin, and mitral valve differed appreciably from normal and that the collagen itself showed an increased number of free hydroxyl groups.

Involvement of the cardiovascular and respiratory systems causes disproportionate morbidity. In this study cardiac disease was directly responsible for the deaths of 8 out of 13 patients. Valvular disease was particularly common, often existing from early childhood, as shown by the catheter studies performed in Cases 23 and 24 at 5 and $2 \frac{1}{2}$ years respectively. During the first 15 years of life clinical evidence of mitral or aortic valve disease was detected in over half the patients. This was often 
asymptomatic. Subsequently more serious problems occurred, possibly secondary to chronic valvular haemodynamic disturbance or to cor pulmonale associated with chronic respiratory tract disease. Necropsy findings in various forms of mucopolysaccharidosis have shown involvement not only of the epicardium, but also of the myocardium, endocardium, and coronary arteries. ${ }^{12} 19$

In the respiratory system, obstruction constitutes the major hazard often exacerbated by acute infectious episodes. The presence of hoarseness and frequent reference to difficulties at intubation suggest that the main problem lies in the region of the larynx and upper trachea. Laryngoscopy and laryngeal xerography in Case 1 have shown gross supraglottic oedema with prominent false cords and antero-postero tracheal flattening. ${ }^{8}$ In Case 2, the trachea was found to be small and flattened at necropsy. Hunter's original patients were noted to have 'uneasy and stertorous' breathing, and similar problems have been reported in other cases. ${ }^{20-22}$

This middle airways obstruction is one of several factors which combine to make general anaesthesia a most hazardous undertaking in this disease. Limitation of movement at the temporo-mandibular joints, macroglossia, and gingival hyperplasia almost totally preclude a clear view with the laryngoscope. The short neck, overhanging epiglottis, and prominent false cords make a blind intubation very difficult, while the small flattened trachea seriously reduces the prospects of a successful emergency tracheostomy. Even if the operation is itself uneventful, the postoperative course is likely to be stormy because of the copious secretions, rigid rib cage, and pre-existing compromised cardiorespiratory function. It is suggested that general anaesthesia should not be lightly undertaken in patients with the mild form of Hunter's syndrome, particularly those in the older age group.

Several authors have noted longstanding papilloedema in mild Hunter's syndrome, ${ }^{3172223}$ and while unexplained, its presence does not necessarily augur badly. Whatever its aetiology, which may include lepto-meningeal thickening with or without internal hydrocephalus, the presence of papilloedema is one of several factors which indicate that the nervous system is not entirely immune to damage in mild Hunter's syndrome. These include the disparity between performance and verbal intelligence scores as noted here and elsewhere, ${ }^{317}$ the high incidence of sensorineural deafness as noted here and possibly explained by the presence of vacuolated cytoplasm in the spinal ganglion cells of the eighth cranial nerve, ${ }^{24}$ and the impaired electroretinography and visually evoked responses noted here and possibly explained by the finding of vacuolated retinal ganglion cells. ${ }^{25}$

Nor is the peripheral nerve entirely spared in this disease. Sural nerve biopsy in a 20 -year-old proved case showed multivacuolated endoneurial fibroblasts and perineurial cells with 'zebra bodies' in the Schwann cells. ${ }^{26}$ Similar changes were noted in sural nerve from 3 brothers with an unusually mild form of the disease manifesting as multiple nerve entrapments. ${ }^{27}$ The progressive quadriparesis noted in the 27-year-old patient in this study may be due to a myelopathy secondary to meningeal thickening in the cervical region as has been documented in at least one other adult with mild Hunter's syndrome. ${ }^{22}$

This disorder is sufficiently rare for it to be unusual for more than a single case to be encountered in a lifetime. Yet its complications are so extensive as to merit the fullest possible medical attention. This paper is presented in the hope that those who do encounter such a case may be alerted to the many problems which may lie ahead.

The observations in this paper are drawn from a thesis submitted to the University of London for the degree of Doctor of Medicine by I D Y.

We thank the patients and their families for their hospitality and co-operation; Dr P F Benson and Dr $R$ Stephens for allowing us to study their patients; Dr I M Archer for performing assays of iduronate sulphatase activity; Mr R G S Mills for invaluable assistance with interpretation of the audiograms; Dr R Marshall and his staff for help and enthusiastic production of the illustrations; the following physicians for allowing us to visit patients under their care or providing clinical details: A Bogdan, R W Emanuel, M A FergusonSmith, O D Fisher, J S Fitzsimmons, A P Fuller, J C Hyde, D $\mathbf{M}$ Johnstone, $\mathbf{R}$ Lindenbaum, J Martin, J G Masterson, J R Moore, K R Norton, and I S Ruthven.

Action Research for the Crippled Child provided financial support.

\section{References}

1 Hunter C. A rare disease in two brothers. Proc $R$ Soc Med 1917; 10: 104-16.

2 Njå A. A sex-linked type of gargoylism. Acta Paediatr $1946 ; 33: 267-86$.

${ }^{3}$ Lichtenstein J R, Bilbrey G L, McKusick V A. Clinical and probable genetic heterogeneity within mucopolysaccharidosis II. Report of a family with a mild form. Johns Hopkins Med J 1972; 131: 425-35.

4 Spranger J. The systemic mucopolysaccharidoses. Ergeb Inn Med Kinderheilkd 1972; 32: 165-265.

5 Young I D, Harper P S. A clinical and genetic study of 
Hunter's syndrome. I. Heterogeneity. J Med Genet 1982; 19: 401-7.

6 Young I D, Harper P S. A clinical and genetic study of Hunter's syndrome. II. Differences between the mild and severe forms. J Med Genet 1982; 19: 408-11.

7 Archer I M, Harper P S, Wusteman F S. An improved assay for iduronate 2-sulphate sulphatase in serum and its use in the detection of carriers of the Hunter syndrome. Clin Chim Acta 1981; 112: 107-12.

8 Young I D, Harper P S. Long term complications in Hunter's syndrome. Clin Genet 1979; 16: 125-32.

9 Hopkins R, Watson J A, Jones J H, Walker M. Two cases of Hunter's syndrome-the anaesthetic and operative difficulties in oral surgery. Br J Oral Surg 1973; 10: 28699.

10 Millman C G, Whittick J W. A sex-linked variant of gargoylism. J Neurol Neurosurg Psychiatry 1952; 15: 253-9.

11 Cockayne E A. Gargoylism (chondro-osteo-dystrophy, hepatosplenomegaly, deafness) in two brothers. Proc $R$ Soc Med 1936; 30: 104-7.

12 Emanuel R W. Gargoylism with cardiovascular involvement in two brothers. Br Heart J 1954; 16: 417-22.

13 Young I D, Harper P S. Psychosocial problems in Hunter's syndrome. Child Care Health Dev 1981; 7: 201-9.

14 Bishton R L, Norman R M, Tingey A. The pathology and chemistry of a case of gargoylism. J Clin Pathol 1956; 9: $305-14$.

15 Smith E B, Hempelmann T C, Moore S, Barr D P. Gargoylism (dysostosis multiplex): two adult cases with one autopsy. Ann Intern Med 1952; 36: 652-67.

16 Neuhauser E B D, Griscom N T, Gilles F H, Crocker A C. Arachnoid cysts in the Hurler-Hunter syndrome. Ann Radiol 1968; 11 : 453-69.

17 McKusick V A. The mucopolysaccharidoses. In: Heritable disorders of connective tissue, fourth edition. St Louis: Mosby, 1972: 521-686.
18 Józsa L. The submicroscopic structure of connective tissue in a case of Hunter's syndrome. Acta Morphol Acad Sci Hung 1971; 19: 301-11.

19 Lindsay $\mathrm{S}$. The cardiovascular system in gargoylism. $\mathrm{Br}$ Heart J 1950; 12: 17-32.

20 DeLange C, Gerlings P G, De Kleyn A, Lettinga T W. Some remarks on gargoylism. Acta Paediatr 1944; 31 : 398-416.

21 Murray J F. Pulmonary disability in the Hurler syndrome (lipochondrodystrophy). A study of two cases. $N$ Engl J Med 1959; 261 : 378-82.

22 Ballenger C E, Swift T R, Leshner R T, El Gammal T A, McDonald T F. Myelopathy in mucopolysaccharidosis type II. (Hunter syndrome). Ann Neurol 1980; 7: 382-5.

${ }^{23}$ Spranger J W, Langer $\mathrm{L} \mathrm{O}$, Wiedmann $\mathrm{H} \mathrm{R}$. Bone dysplasias. An atlas of constitutional disorders of skeletal development. Philadelphia: Saunders, 1974: 152-6.

24 Wolff D. Microscopic study of temporal bones in dysostosis multiplex (gargoylism). Laryngoscope 1942; 52: 218-23.

25 Topping T M, Kenyon K R, Goldberg M F, Maumenee A E. Ultrastructural ocular pathology of Hunter's syndrome. Arch Ophthalmol 1971; 86: 164-77.

${ }^{26}$ Swift T R, McDonald T F. Peripheral nerve involvement in Hunter syndrome (mucopolysaccharidosis II). Arch Neurol 1976; 33: 845-6.

27 Karpati G, Carpenter S, Eisen A A, Wolfe L S, Feindel W. Multiple peripheral nerve entrapments. An unusual phenotypical variant of the Hunter syndrome (mucopolysaccharidosis II) in a family. Arch Neurol 1974; 31 : 418-22.

Correspondence to Dr I D Young, Department of Child Health, Clinical Sciences Building, Leicester Royal Infiımary, PO Box 65, Leicester LE2 7LX.

Received 15 April 1982 